\title{
Clinical and Epidemiologic Profile of Chronic Pancreatitis, A Retrospective Study in Eastern Nepal
}

\author{
Rabin Sharma ${ }^{1}$, Bickram Pradhan ${ }^{2}$, Prahlad Karki ${ }^{3}$, Manish Subedi ${ }^{4}$ \\ ${ }^{1}$ Gastroenterologist, Department of Gastroenterology and Hepatology, Nepal Mediciti Hospital, Bhaisepati, Lalitpur, Nepal \\ ${ }^{2}$ Professor and Chair, Division of Gastroenterology, Department of Internal Medicine, BPKIHS, Dharan, Nepal \\ ${ }^{3}$ Professor and Head, Department of Internal Medicine, BPKIHS, Dharan, Nepal \\ ${ }^{4}$ Assistant Professor, Department of Internal Medicine, BPKIHS, Dharan, Nepal
}

\section{DOI: https://doi.org/10.3126/jaim.v7i2.23487}

Keywords: Calculi, Chronic Pancreatitis, Ductal dilatation, Nepal, Pseudocyst

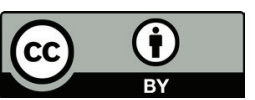

This work is licensed under a Creative Commons Attribution 3.0 Unported License.

\begin{abstract}
Background and Aims: Chronic pancreatitis is a condition characterized by chronic inflammatory and fibrotic changes in the pancreas leading to irreversible parenchymal damage and loss of glandular function. This retrospective study was conducted to study the clinicepidemiologic profile of chronic pancreatitis in eastern Nepal.
\end{abstract}

Methods: All adult patients admitted with chronic pancreatitis from June 2014 to June 2016 were included in this study. Data pertaining to demographics and clinical profile was obtained by retrospective chart review.

Results: A total of $(n=55)$ patients were enrolled in the study with a median age of 28 years. Idiopathic pancreatitis was the most common form of chronic pancreatitis $(n=37$, $67.3 \%)$ and alcoholic chronic pancreatitis accounted for about a third of cases $(n=18,32.7 \%)$. Abdominal pain was a presenting symptom in all the cases $(\mathrm{n}=55,100 \%)$. Thirtyseven patients $(67.3 \%)$ had diabetes mellitus. Ductal dilatation $(n=55,100 \%)$ and calculi $(n=43,83.6 \%)$ were the most common findings on imaging using ultrasonography and Computed tomographic scan of abdomen). All the patients were receiving medical therapy. Most patients receiving medical therapy were on opioids $(n=37,67.3 \%)$ or pancreatic supplements $(\mathrm{n}=18,32.7 \%)$. Complications were seen in only nine patients $(16.4 \%)$. All of them had pseudocyst.

Conclusions: In this study, idiopathic chronic pancreatitis (CP) was observed as the most common etiologic form of $\mathrm{CP}$ unlike $\mathrm{CP}$ related to alcohol use in other similar studies. $\mathrm{CP}$ related to alcohol use was seen as the second most common etiologic form. Diabetes was the most commonly associated comorbidity in our CP cohort. This study was performed in a small study population and is limited by several factors including statistical power. Larger studies are warranted to study the etiologic forms and outcomes of CP in Nepalese population.

\section{Introduction}

Chronic pancreatitis (CP) is a syndrome involving progressive inflammatory changes in the pancreas that result in permanent structural damage, which can lead to impairment of exocrine and endocrine function. ${ }^{1} \mathrm{CP}$ is widely prevalent in Asia with a reported prevalence of $125 / 100,000$ population from a study in India. ${ }^{2} \mathrm{~A}$ long history of heavy alcohol consumption is the most common cause of chronic pancreatitis. $30-40 \%$ of patients

\section{Corresponding Author}

Dr Rabin Sharma, MD, DM

Department of Gastroenterology and Hepatology

Nepal Mediciti Hospital, Bhaisepati, Lalitpur, Nepal

Tel no. 009779852049497

Email: docrabinsharma@gmail.com 
with chronic pancreatitis are considered to have "Idiopathic" chronic pancreatitis. ${ }^{3} \mathrm{CP}$ is characterized by abdominal pain in the earlier stages with diabetes mellitus later in the natural course of the disease. In this study, we sought to ascertain the clinical profile of patients with chronic pancreatitis in eastern Nepal, especially with regard to risk factors, clinical features and therapeutic modalities.

\section{Materials and Methods}

This is a retrospective hospital based study. Adult subjects ( $\geq 18$ years of age) with characteristic clinical features, laboratory parameters and radiological findings suggestive of chronic pancreatitis admitted in Medicine wards from June 2014 to June 2016 were included in the study. The diagnosis of CP was based on the characteristic clinical features, laboratory test, and imaging diagnostics.

\section{Definitions and Diagnostic Criteria}

Chronic pancreatitis was defined by features of irreversible pancreatic inflammation, i.e., clinical, structural or functional abnormality of the pancreas. ${ }^{4}$ The presence of pancreatic calculi or ductal irregularity/parenchymal atrophy was determined at imaging using ultrasonography and CT scan. Diabetes mellitus was diagnosed based on the American Diabetes Association criteria for diabetes described as the fasting plasma glucose value was equal to, or greater than, $126 \mathrm{mg} / \mathrm{dL}$ confirmed on two occasions and/or a plasma glucose value equal to, or greater than, $200 \mathrm{mg} / \mathrm{dL}$ after a two-hour glucose load confirmed on two occasions and a $\mathrm{HbA} 1 \mathrm{C}$ value of $\geq 6.5 \%$ Alcohol intake was considered significant in chronic pancreatitis patients who had been taking the equivalent of $80 \mathrm{gm}$ or more of ethanol/day for at least five years.

"Tropical pancreatitis", was defined on the basis of three most distinctive features of the disease: i) onset at less than 30 years of age; ii) a BMI less than $18 \mathrm{~kg} / \mathrm{m} 2$; iii) patients with chronic pancreatitis in absence of history of alcohol use or presence of any other obvious cause of pancreatitis, i.e. Smoking, Autoimmune pancreatitis. ${ }^{5,6} \mathrm{We}$ then sought to determine how many among the current cohort would fit these criteria. Patients having features of recurrent acute pancreatitis were excluded from the study

\section{Methods of Recruitment of the Patients}

Informed consent from patients was obtained per institutional policy and this study was approved by the institutional review board. Data was obtained by retrospective review of medical records. All the patients with case definition and inclusion criteria of chronic pancreatitis admitted in the medicine wards from June 2014 to June 2016 were enrolled in this study.

Data pertaining to demographics and clinical characterstics were collected based on a proforma as depicted in Table (Make a Table with Summary Statistics, so that it will depict the proforma and summarize the demographic characterstics and variable studied. Demographic characteristics included age, sex, race, occupation, mode of presentation of illness, history of Diabetes and the treatment received, BMI and Socioeconomic status. Socioeconomic status was assessed according to the Kupuswammy index modified for Nepali rupees. ${ }^{7}$

\section{Study parameters.}

After extensive survey of the medical records, the following parameters were collected: results of investigations, imaging study results, mode of treatment of diabetes, analgesics, the use of pancreatic enzyme supplements, frequency of endotherapy and surgery.

\section{Statistical Analysis}

Data was entered in MS Excel 2007 and converted to SPSS 11.5 version for statistical analysis. Descriptive and inferential statistics was used to describe the data in number, frequency, mean and standard deviation. Quantitative data was described in mean and standard deviation considering the normality of data. Median and interquartile range was calculated in the case of skewed distribution. Unpaired ' $t$ ' test was applied to compare two independent means and their significance level was estimated using $95 \%$ confidence interval and all hypothesis testing was 2-tailed, and $\mathrm{P} \leq 0.05$ was considered statistically significant.

\section{Results}

A Total of 55 patients were enrolled in the study. Demographic Charactertics is summarized in Table 1.

\begin{tabular}{|c|c|}
\hline \multicolumn{2}{|l|}{ Table 1. Demographic Profile. } \\
\hline Demographic Characteristics & All $(\mathrm{n}=55)$ \\
\hline Age (Years) $($ Mean \pm SD) & $58.18 \pm 9.33$ \\
\hline Gender Male & $37(67.3 \%)$ \\
\hline Female & $18(32.7 \%)$ \\
\hline $\mathrm{BMI}(\mathrm{Mean} \pm \mathrm{SD})$ & $680.33 \pm 331$ \\
\hline Smoking & $18(32.7 \%)$ \\
\hline Alcohol & $18(32.7 \%)$ \\
\hline Alcohol and Smoking & $18(32.7 \%)$ \\
\hline \multicolumn{2}{|l|}{ Socioeconomic status } \\
\hline Upper class & $0(0 \%)$ \\
\hline Upper middle class & $2(3.6 \%)$ \\
\hline Middle/lower middle class & $25(45.5 \%)$ \\
\hline Lower/ upper lower class & $28(50.9 \%)$ \\
\hline Lower class & $0(0 \%)$ \\
\hline
\end{tabular}

Factors related to the disease

Most common presentations with which the patients were admitted were Pain abdomen and Diabetes Mellitus. The distribution of presenting complaints is listed in (Table 2).

\begin{tabular}{|l|l|}
\hline \multicolumn{2}{|l|}{$\begin{array}{l}\text { Table.2 Distribution of presenting complaints observed in } \\
\text { patients with Chronic Pancreatitis. }\end{array}$} \\
\hline Presenting Complaints & Frequency $(\mathrm{n}=55)$ \\
\hline Pain abdomen & $55(100 \%)$ \\
\hline Diabetes Mellitus & $37(67.3 \%)$ \\
\hline Weight loss & $28(50.9 \%)$ \\
\hline Chronic Diarrhea & $9(16.4 \%)$ \\
\hline
\end{tabular}

Profile of Diabetes Mellitus.

All Patients with Diabetes Mellitus were admitted for sugar control. Of the 37 diabetic patients, $18(48.6 \%)$ were taking oral hypoglycemic agents, $9(24.3 \%)$ were taking Insulin and $10(27 \%)$ were not on any medication during the time of admission. None of the patients had evidence of Diabetic Ketoacidosis. Nine patients $(24.3 \%)$ had evidence of neuropathy.

$\underline{\text { Risk factor assessment of chronic pancreatitis }}$ 


\section{Imaging modalities}

Ultrasound data was available in all of the 55 patients $(100 \%)$ and the most common findings were dilated duct intraductal calculi and pancreatic atrophy with pancreatic parenchymal calcification. There was no evidence of common bile duct dilatation. evidence of common bile duct dilatation. Common findings noted on imaging are listed in (Table 3) and illustrated in the (Figure).

\begin{tabular}{|l|l|l|}
\hline \multicolumn{3}{|l|}{ Table 3.Common findings noted on imaging. } \\
\hline Variable & Ultrasound (n=55) & CT (n=55) \\
\hline Dilated duct & $55(100 \%)$ & $55(100 \%)$ \\
\hline Intraductal Calculi & $43(83.6 \%)$ & $43(83.6 \%)$ \\
\hline $\begin{array}{l}\text { Atrophy with } \\
\text { pancreatic parenchymal } \\
\text { calcification }\end{array}$ & $20(36.4 \%)$ & $20(36.4 \%)$ \\
\hline Mass & $0(0 \%)$ & $0(0 \%)$ \\
\hline $\begin{array}{l}\text { Common bile duct } \\
\text { dilatation }\end{array}$ & $0(0 \%)$ & $0(0 \%)$ \\
\hline
\end{tabular}

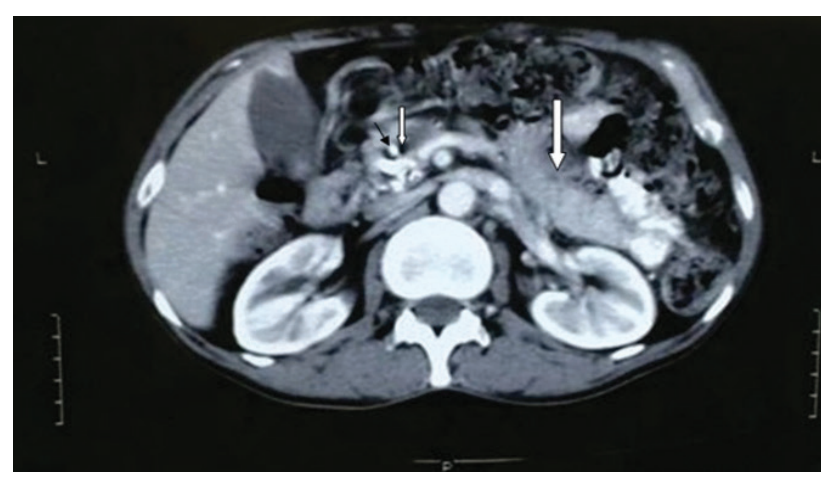

Fig. Contrast enhanced axial CT scan shows atrophic pancreatic parenchyma (large white arrow) with multiple calcifications in body and head region along with dilated main pancreatic duct (small white arrow) and a calculus in the main pancreatic duct (small black arrow).

\section{Treatment modalities for chronic pancreatitis}

All 55 patients (100\%) were receiving medical therapy for the treatment of chronic pancreatitis. None of them had undergone surgery or received endotherapy. Eighteen patients $(32.7 \%)$ were on pancreatic supplements and 37 patients $(67.3 \%)$ were on opioids for the treatment of pain. None of the patients were taking NSAIDS, antioxidants or any other modality of pain relief.

Complications of chronic pancreatitis

Nine patients (16.4\%) had evidence of pseudocyst. None of the patients had biliary obstruction, pancreatic neoplasm, ascites or gastrointestinal bleeding.

\section{Discussion}

We report the results of a Tertiary Care Center based on this retrospective study of subjects with chronic pancreatitis in Eastern Nepal. The results of our study conducted on 55 patients. Idiopathic pancreatitis is the most common form of chronic pancreatitis in this study, accounting for about twothirds of the cases, one third of the patients (all male) had history of alcohol use. The median age of the study subjects was 28 years (21-44) with men comprising around $68 \%$ of the cases.
It is important to note that chronic pancreatitis was seen in a much younger population in our study. Genetic tests like cationic trypsinogen, CFTR, and SPINK1 mutation was not performed due to availability and resource constraint. Details pertaining to dietary habit could not be addressed due to retrospective nature of the study. Alcohol could be a contributing factor since alcohol use was present in more than one third of the study population. Chronic pancreatitis observed in younger Nepalese population needs to be investigated in larger epidemiologic studies.

Previous reports have shown that most patients get diagnosed above the age of 40 , most of them being men. ${ }^{8-10}$ Another interesting observation in the study was the average BMI of the patients which was in the lower range of normal $(19.85 \pm 2.06 \mathrm{~kg} /$ $\mathrm{m} 2)$. Similarly, most of the patients were in the middle/lower middle and lower/upper lower class of Modified Kupuswamy Index possibly highlighting the fact that nutrition and socioeconomic status might play a role in the pathogenesis of chronic pancreatitis in developing countries. S Shrestha et al conducted a study in Kathmandu in 108 patients of chronic pancreatitis. Most patients were non-alcoholic and the etiological factor in this group may be attributed to the nutritional, idiopathic, hereditary etc, though the single most common etiological factor seemed to be alcohol. ${ }^{11}$

The male predominance of alcoholic chronic pancreatitis in Nepal is likely due to the fact that alcoholism is quite uncommon amongst Nepali women. The mean daily intake, as well as the duration of the consumption of alcohol, is similar to that reported by subjects with alcoholic chronic pancreatitis from the developed world. Smoking being more common in men in this part of the world most of the smoking subjects were men. Smoking and alcohol were coexistent: all alcoholic patients were smokers as well. Smoking is now recognized as an independent risk factor for chronic pancreatitis, a leading risk factor for pancreatic cancer. $^{12}$

Several studies from South India on 'Tropical chronic pancreatitis' has shown that the disease occurs in young subjects (16-30 years) with significant malnutrition, tendency of exocrine and endocrine dysfunction and a higher risk for malignancy. ${ }^{13,14}$ In this series, using a rigid age-based cut-off, 8 of the 55 subjects $(14.5 \%)$ could be defined as having the classical form of 'tropical' chronic pancreatitis.

All the subjects in the study had epigastric pain abdomen as the initial presenting complaint. Severe pain decreases appetite and limits food consumption, contributing to weight loss and malnutrition. Around half of the patients had a history of significant weight loss. Abdominal pain is the most important clinical problem in patients with chronic pancreatitis which has a significant impact on the quality of life. ${ }^{15,16}$ Only around $16 \%$ of study subjects presented with history of chronic diarrhea.

This study also documents the clinical profile of chronic pancreatitis-related diabetes. Diabetes was present in around $68 \%$ of the subjects. A very peculiar observation made in the all the diabetic subjects were presence of alarmingly high levels of blood sugars on presentation. The average fasting blood sugar, post prandial blood sugar and glycosylated hemoglobin (Hba1C) were $245 \pm 40.58 \mathrm{mg} / \mathrm{dl}, 445.22 \pm 99.04 \mathrm{mg} / \mathrm{dl}$ and $11.41 \pm 0.37 \mathrm{mg} /$ $\mathrm{dl}$ respectively. Diabetes mellitus secondary to pancreatic diseases (such as chronic pancreatitis) is classified as pancreatogenic diabetes or type $3 \mathrm{c}$ diabetes mellitus according to the current classification of diabetes mellitus. ${ }^{17,18}$ Diabetes can be both be cause and effect of chronic pancreatitis. 
The most common findings on imaging, ultrasound and ct abdomen were dilated main pancreatic duct and calculi. Pancreatic histology is the gold standard on the basis of which the sensitivity, specificity, and accuracy of any of these diagnostic tests can be determined. However the procedure is risky and the findings can be misleading at times. ${ }^{19,20}$

In our study most of the patients were receiving either opioid analgesic or pancreatic supplement for pain relief or steatorrhea. Possible benefit of antioxidant therapy in pain management in $\mathrm{CP}$ is emerging. ${ }^{21}$ Commercial food supplements are not superior to balanced homemade diet in improving malnutrition in patients with CP. ${ }^{22}$ Replacement pancreatic enzymes are often effective in treating the malabsorption and steatorrhea.

More than half of the study subjects did not improve with the standard pain management and had persistent symptom. This highlights the need of newer therapeutic modalities for pain management including possibly antioxidants and endotherapeutic procedures eg. ERCP and a specialized pancreatic surgical unit. This study had several limitations. Obviously the sample size was not adequate given the study period. Furthermore the design of the study being a retrospective analysis there were occasionally missing data and the lack of information regarding diet and nutrient. Further the lack of genetic tests (which includes cationic trypsinogen, CFTR, and SPINK1 mutation) and ERCP (Endoscopic retrograde pancreaticography)/MRCP (Magnetic resonance cholangiopancreaticopgraphy) to diagnose conditions including pancreatic divisum and duct obstruction owing to various causes, severely limited the possibility of a deeper analysis into the etiological assesment of CP.

In conclusion this study assumes importance in the light of a previous report suggesting a high prevalence of chronic pancreatitis in the Asia pacific region. The growing awareness and recognition of the disease and its complications among the medical society in Nepal is helping in shedding some light into the characteristics of this underreported disease. But there is a need for a larger population based studies to understand the true magnitude and burden of this disease in Nepal.

\section{Acknowledgement}

I would like to sincerely thank Prof. Dr. Bickram Pradhan MD, Professor and Chair, Division of Gastroenterology, under whose supervision this paper was prepared. I would like to express my special gratitude to the Head of the Department Prof. Dr. Prahlad Karki MD, for his support and encouragement. I would also like to thank all my patients, colleagues and my family members without whose support the completion of this paper would not have been possible.

\section{References}

1. Steer ML, Waxman I, Freedman S. Chronic pancreatitis. N Engl J Med 1995; 332:1482-90.

2.Tandon RK, Sato N, Garg PK. Chronic pancreatitis: AsiaPacific consensus report. J Gastroenterol Hepatol 2002;17: 508-18.

3. Garg PK, Tandon RK. Survey on chronic pancreatitis in the Asia-Pacific region. J Gastroenterol Hepatol 2004; 19: 998 1004.

4. Etemad B, Whitcomb DC. Chronic pancreatitis: Diagnosis, classification, and new genetic developments. Gastroenterology 2001; 120:682-707.

5. Balakrishnan V. Pancreatic tropicale. In: Bernades P, Hugier M. Eds. Progress en Hepatogastroenterologie: Maladies Du Pancreas Exocrine. Paris: Doin editeurs 1987; 207-27.
6. Mohan V, Premalatha G. Fibrocalculous pancreatic diabetes. Int J Diabetes 1995; 3:71-82.

7. Ghosh A, Ghosh T. Modification of Kuppuswamys socioeconomic status scale in context to Nepal. Indian Pediatr. 2009 Dec;46(12):1104-5.

8. Yadav D, Lowenfels AB. The epidemiology of pancreatitis and pancreatic cancer. Gastroenterology 2013; 144:1252-61.

9. Hirota M, Shimosegawa T, Masamune A, et al. The sixth nation-wide epidemiological survey of chronic pancreatitis in Japan. Pancreatology 2012; 12:79-84.

10. Yadav D, Timmons L, Benson JT, et al. Incidence, prevalence, and survival of chronic pancreatitis: A population-based study. Am J Gastroenterol 2011; 106:2192-9.

11. Shrestha S, Rao A. The clinical study of chronic pancreatitis. Nepal Med Coll J. 2004; 6(1):32-5.

12. Lin Y, Tamakoshi A, Hayakawa T et al. Cigarette smoking as a risk factor for chronic pancreatitis: a case-control study in Japan. Research Committee on Intractable Pancreatic Diseases. Pancreas 2000; 21:109-14.

13. Chari ST, Mohan V, Pitchumoni CS, et al. Risk of Pancreatic Carcinoma in tropical calcifying pancreatitis: an epidemiologic study. Pancreas 1994; 2:62.

14. Mori M, Hariharan M, Anandakumar M, et al. A case control study on the risk factors for pancreatic diseases in Kerala, India. Hepato Gastroenterology 1999; 46:25-30

15. Mullady DK, Yadav D, Amann ST, et al. NAPS2 Consortium. Type of pain, pain-associated complications, quality of life, disability, and resource utilization in chronic pancreatitis. A prospective cohort study. Gut 2011; 60:77-84.

16. Amann ST, Yadav D, Barmada MM, et al. Physical and mental quality of life in chronic pancreatitis: A case-control study from the North American Pancreatitis Study 2 cohort. Pancreas 2013; 42:293-300.

17. Expert Committee on the Diagnosis and Classification of Diabetes Mellitus. Report of the expert committee on the diagnosis and classification of diabetes mellitus. Diabetes Care 2003; 26 Suppl 1: S5-S20

18. American Diabetes Association. Diagnosis and classification of diabetes mellitus. Diabetes Care 2011; 34 Suppl 1: S62-S69

19. Forsmark CE. Management of chronic pancreatitis. Gastroenterology 2013; 144:1282-91.

20. Kloppel G, Maillet B. Pathology of chronic pancreatitis. In: Beger HG, Warshaw AL, Buchler MW, et al, editors. The pancreas. Malden, Mass.: Blackwell Science; 1998. pp 720-3.

21. Bhardwaj P, Garg PK, Maulik SK et al. A randomized controlled trial of antioxidant supplementation for pain relief in patients with chronic pancreatitis. Gastroenterology 2009; 136:149-159.

22. Singh S, Midha S, Singh N, et al Dietary counseling versus dietary supplements for malnutrition in chronic pancreatitis: a randomized controlled trial. Clin Gastroenterol Hepatol. 2008; 6:353-9. 